\title{
ACUMULAČ̃̃O FLEXÍVEL, TÉCNICAS DE INOVAÇ̃̃O E GRANDE INDÚSTRIA DO FITNESS: O CASO CURVES BRASIL
}

\author{
Fernando Mascarenhas* \\ Carlos Alexandre Vieira ${ }^{* *}$ \\ Taianne Marya Alves Marques ${ }^{* * *}$ \\ Paulo José Albino Borges*** \\ BRUno de Oliveira e SiLva** \\ Willian Batista dos SANTOS ${ }^{* * *}$
}

\section{RESUMO}

Este texto apresenta uma investigação relativa às características e tendências da acumulação flexível que embalam o desenvolvimento do mercado do fitness. Trata-se de um estudo a partir do caso da Curves Brasil. Para tanto, buscamos confrontar e examinar a implementação de técnicas organizacionais com eficácia evidenciada em escala mundial através do princípio da verificação de um caso particular e real de desenvolvimento. As conclusões apontam para novas técnicas de inovação utilizadas para resolver a difícil equação enfrentada pelo setor no que diz respeito à atração e à retenção de consumidores.

PALAVRAS-CHAVE: lazer - cultura - educação - Educação Física - academias de ginástica.

\section{INTRODUÇÃO}

$\mathrm{O}$ lazer tem ocupado lugar de relevo na sociedade contemporânea. Todavia, bem distintas das práticas sociais de recreação e divertimento presentes em época anterior, as experiências de lazer atuais estão cada vez mais subordinadas à forma mercadoria. No caso do Brasil, tal transformação se evidencia a partir da década de 1990, no bojo da desintegração dos direitos sociais, quando do início do processo de implementação das políticas neoliberais e estruturação do Estado Mínimo. Diante da reorientação na destinação dos gastos do fundo público e re-

\footnotetext{
Professor da Faculdade de Educação Física da UFG e do Programa de PósGraduação em Educação Física da UnB.

** Professor da Faculdade de Educação Física da UFG.

*** Licenciados em Educação Física pela UFG e integrantes do GEPELC-UFG.
} 
cuo da participação estatal na implementação de políticas distributivas asseguradoras do acesso aos direitos sociais, bem como do processo de desregulação econômica consoante aos interesses privatistas, acrescem os investimentos na produção do lazer mercantil. ${ }^{1}$

Ocorre que frente à intensificação da concorrência intercapitalista, com a desregulação econômica em escala internacional, seguindo a lógica da acumulação flexível, ${ }^{2}$ que combina expansão extensiva, pela abertura de novos mercados em regiões até então pouco exploradas, e intensiva, induzida pelo mimetismo periférico dos hábitos e estilos de vida divulgados a partir dos centros mais dinâmicos do mercado mundial, o capital volta seus investimentos para setores de maior liquidez, sempre em busca de maiores taxas de lucro. Nesta direção, bens e serviços culturais revelam-se como mercadorias de superfluidade, assegurando menor tempo de giro e rápida valorização. Não é por acaso, portanto, que aumenta a oferta e o consumo de diversão, jogos, esportes, espetáculos e distrações. A liquidez do capital investido neste tipo de serviço é bem maior do que aquele convertido na produção industrial, e como existem limites para a acumulação e para o giro de bens físicos, não é de estranhar que o mercado se volte para o fornecimento de serviços bastante efêmeros em termos de consumo, chamando atenção aí o mercado do fitness (HARVEY, 2000).

A título de exemplo, conforme pesquisa da Fundação Getúlio Vargas (FGV), somente a Indústria do Esporte no Brasil movimentou sozinha, de 1996 a 2000, R\$ 24 bilhões por ano, alcançando o crescimento médio de $12,34 \%$, enquanto o PIB brasileiro avançou à taxa média anual de apenas $2,25 \%$ verificados no mesmo período. Metade desta soma é atribuída à indústria de artigos esportivos, como roupas, calçados e equipamentos. Outra parte advém dos serviços mais ligados ao esporte propriamente dito, como sua prática em clubes e academias de ginástica, arrecadação em estádios e outros espaços, marcas e direitos de imagem, marketing e comunicação esportiva. No que se refere especificamente ao segmento do fitness, segundo levantamento da Associação Brasileira de Academias (ACAD), havia no país, em 2000, 7.102 academias de ginástica em funcionamento (KASZNAR; GRAÇA FILHO, 2002). E dados mais atualizados confirmam a tendência de crescimento do setor. Em 2005, o número de academias já saltava para 20.000, alçando o Brasil ao posto de país com a maior proporção de 
academias por habitante. Mais de 3,2 milhões de brasileiros freqüentavam academias (COSTA, 2005).

Obviamente que este crescimento é estimulado por uma série de técnicas de inovação que se processam continuamente no universo das academias de ginástica. Além da promessa de felicidade difundida por uma verdadeira idolatria do corpo satelitizada pelo alto através do marketing e da moda, bem como de novas atrações em termos de práticas e técnicas corporais que de tempo em tempo são descartadas pelo processo obsoletismo planejado, todo o aparato, design e incremento de novos e modernos equipamentos, a segmentação das academias para nichos específicos de consumidores, o casamento da mercantilização das práticas corporais em ambientes de academia de ginástica com outros variados tipos de comércio, são determinações importantes a serem observadas no todo deste movimento (MÉSZÁROS, 2002).

Deste modo, nosso problema consiste em identificar algumas das características, tendências, contradições e implicações da lógica que embala o desenvolvimento do mercado do fitness. No tocante ao particular desta pesquisa, a partir de um estudo de caso realizado junto a Curves Brasil, ${ }^{3}$ dedicamo-nos a investigar como as técnicas de inovação são incorporadas à gestão das academias de ginástica, visando maior eficiência e eficácia na atração e retenção de consumidores. Em sendo assim, apresentamos tematicamente algumas reflexões, resultados e conclusões deste estudo, com especial atenção para os desdobramentos e nuanças que envolvem a subordinação das práticas corporais à forma mercadoria em ambientes de academias de ginástica.

\section{A GRANDE INDÚSTRIA DO FITNESS}

A noção geral de Indústria Cultural, da qual se desdobra aqui a noção mais específica de Indústria do Fitness, refere-se ao processo de padronização e racionalização das técnicas de produção e distribuição dos bens culturais mercantilizados (ADORNO; HORKHEIMER, 1985). Quanto à segunda, esta guarda relação mais de perto com o processo de produção e distribuição das técnicas e práticas corporais subordinadas à razão instrumental e ao comércio nas academias de ginástica. Todavia, há de se alertar que tanto a expressão Indústria Cultural como a expressão Indústria do Fitness podem nos sugerir uma idéia de 
homogeneidade, ocultando as tendências monopolistas de concentração e centralização típicas do desenvolvimento desigual que apanha também esta atividade econômica.

No tocante à Indústria Cultural, em conformidade com as determinações dadas no contexto do capitalismo avançado, tal noção é atualizada através da expressão categorial Indústria Cultural Globalizada, que busca explicar o processo de desenvolvimento do capital monopolista que se expressa pela formação de grandes conglomerados empresariais atuando na produção e comércio de serviços e bens culturais, muitas vezes de base transnacional (ORTIZ, 2000). O que estamos sugerindo, no que se refere à Indústria do Fitness, é que neste movimento expansivo, que é desigual, existe, de um lado, a Grande Indústria do Fitness e, de outro, a Pequena Indústria do Fitness ${ }^{4}$ Apoiada nos princípios da acumulação flexível, sintonizada tanto com o consumo em escala, como também orientada para o atendimento dos mais variados estilos de vida - ou seja, combinando massificação e segmentação -, a Grande Indústria do Fitness está sempre em busca de ofertas originais e novidades que renovem seu poder de atração de novos e potenciais consumidores.

Advertimos, porém, que a atratividade e o fortalecimento do poder competitivo de qualquer negócio, obrigatoriamente, requerem altos investimentos, o que reforça as tendências de concentração e centralização do capital, processo decorrente de fatores como concorrência, acesso ao crédito, incorporações, fusões, técnicas de inovação, entre outras. No mercado do fitness, dentre as diversas estratégias utilizadas para ganho de competitividade, podemos destacar o sistema de franquias. ${ }^{5}$ Neste particular, o modo e a velocidade como as franquias se difundem impressionam, pois "a fabricação industrial da cultura e a existência de um mercado mundial exigem uma padronização dos produtos, onde a corporação global, a um baixo custo, opera em todo mundo como se ele fosse uma entidade singular; ela vende as mesmas coisas, e da mesma maneira em todos os lugares" (ORTIZ, 2000, p. 32).

Pertencente ao quadro da Grande Indústria do Fitness, a Curves, em especial, não obstante o fato de ser a franquia que mais cresce no mundo, é a que cresce mais rápido, numa média de 200 novas unidades por mês. Hoje são mais de 11.500 em 27 países, com unidades, por exemplo, nos Estados Unidos, Canadá, vários países da Europa e América do Sul, Caribe, México, Austrália, Nova Zelândia 
e outros. Somente no Brasil, já são 126 unidades, distribuídas pela Bahia, Ceará, Distrito Federal, Goiás, Minas Gerais, Pará, Rio de Janeiro, Rio Grande do Norte e São Paulo. ${ }^{6}$ E seguindo uma lógica de padronização, em qualquer unidade da Curves podemos encontrar as mesmas técnicas de inovação no que se refere à atração e retenção de consumidores, com destaque para a segmentação feminina, o ambiente estético das academias, a tecnologia de aparelhos, a metodologia de treino e a relação de troca estabelecida. Analisaremos, por conseguinte, algumas das técnicas de inovação mais evidentes no processo de gestão e organização na comercialização do fitness operada pela Curves Brasil, a começar pela mais importante, o diferencial de uma academia só para mulheres.

\section{ACADEMIA SÓ PARA MULHERES}

Observando o mercado do fitness, percebemos que, combinado ao processo de massificação, a segmentação das academias para nichos específicos de consumidores opera na base da disjunção entre a produção de riquezas e a satisfação das necessidades humanas, estimulando a criação de novas necessidades de acordo com os interesses de vendabilidade (MÉSZÁROS, 2002). Assim, o comércio de práticas corporais, voltado ao segmento feminino, ganha força e legitimidade, especialmente, devido à intensificação das preocupações com a estética relacionada aos padrões de beleza vigentes que, cada vez mais, aparece colada à própria noção de saúde. Isto é, beleza e saúde, saúde e beleza, mais e mais, são qualidades igualadas. Nesse sentido, as academias de ginástica criam e recriam novas práticas corporais como uma alternativa para se vender um corpo mais belo e saudável. E como os meios de comunicação constituem um poderoso instrumento no processo de mundialização da cultura, nota-se o surgimento de uma nova utopia vinculada ao corpo e a relação entre saúde e beleza.

As informações sobre os problemas de saúde e as formas de se chegar à aparência de beleza circulam pelo mundo, atravessam as diferentes culturas pela força de penetração dos meios de comunicação de massa, levando a uma homogeneização das tecnologias do corpo e a uma tendência de mundialização desta utopia, não mais como um lugar, mas 
como uma construção de um sonho que abrange toda extensão planetária, porém, não toda humanidade (SILVA, 2001, p. 54-55).

Desta forma, os novos valores atribuídos ao corpo estão diretamente ligados ao mercado da estética. As promessas da Grande Indústria do Fitness contam com um avançado aparato tanto no campo do marketing e da propaganda, responsável em criar novas necessidades, como no campo científico, que legitima o discurso da saúde atrelado à beleza, ambos promovem uma identificação do consumidor com produtos e serviços propostos pelo setor. E nesse contexto, percebemos que as exigências de adequação às imposições do mercado recaem com maior ênfase sobre o corpo da mulher. Isso fica evidente ao observarmos os produtos e serviços produzidos e consumidos em maior escala para e pelo segmento feminino. Porém, faz-se importante destacar que o sucesso na comercialização destas práticas necessita da identificação do consumidor que se busca seduzir. Assim, as práticas corporais ambientadas em academias de ginástica devem se apresentar de modo a encantar suas potenciais consumidoras, objetivando sua identificação com o serviço oferecido.

Expor e apresentar as mercadorias; decoração do ponto de vendas, sua arquitetura, a iluminação, as cores, o fundo musical, os aromas; a equipe de vendas, seu aspecto exterior, seu comportamento; a concretização da venda - cada momento de mudança de forma das mercadorias e as circunstâncias nas quais ocorre e influenciam são abrangidos pelo cálculo fundamental da valorização e configurados funcionalmente (HAUG, 1997, p. 100).

A segmentação confere ao capitalismo uma nova possibilidade e se apresenta como uma estratégia de produção específica de bens e serviços. Os artifícios utilizados para a comercialização das diferentes práticas corporais exclusivas para mulheres são, portanto, previamente calculadas e pensadas de modo a conquistar a futura aluna consumidora. "Os meios empregados pela propaganda são, geralmente, aqueles que se utilizam, de maneira subliminar ou não, de imagens de juventude em liberdade, imagens de opulência e saúde, temperadas pelo erotismo, para vender os mais diversos produtos" (SILVA, 2001, p. 60). No terreno das práticas corporais, é fato que a segmentação feminina não é nova, pois as mulheres não costumam se exercitar da mesma forma que os homens. ${ }^{7}$ Todavia, 
o mercado forja novas expectativas e necessidades entre o público feminino, ressignificando seus produtos e serviços segundo distintos comportamentos, hábitos de consumo, valores e estilos de vida até então não tão evidenciados.

Nesse sentido, de um lado, a ampliação e a intensificação dos processos relativos à fetichização do feminino alteram a estrutura de necessidades de indivíduos e coletividades, imprimindo as características de um segmento de mercado onde a tecnocracia da juventude e da sensualidade "significa o domínio sobre as pessoas exercido em virtude de sua fascinação pelas aparências artificiais tecnicamente produzidas" (HAUG, 1997, p. 67). Deste modo, com a venda e comércio de equipamentos e práticas corporais específicas para o segmento feminino, atendendo as demandas competitivas do mercado do fitness, podemos perceber uma nova tendência entre as academias de ginástica: as academias só para mulheres. Conquanto, a Curves volta-se para o perfil de mulher moderna e independente que, frente à aceleração dos ritmos e processos diários de sua vida cotidiana, resiste a entrar em uma academia por falta de tempo. Isto sem falar do perfil de mulher inibida, que resiste em freqüentar uma academia convencional por vergonha de seu próprio corpo, estranho aos arquétipos e às imagens corporais de juventude, saúde e beleza estandardizadas pela mídia e legitimadas pela tecno-ciência.

Quem reluta em entrar em uma academia vive arrumando desculpas: falta de tempo, vergonha de não estar em forma no meio de tanta gente "sarada", dificuldade em lidar com os exercícios e mesmo o constrangimento de se sentir um peixe fora d'água num ambiente cheio de jovens e azaração. Mas agora nada mais disso é pretexto para não seguir um programa de atividade física, com a chegada da Curves ao Brasil. A Curves é uma espécie de clube só para mulheres, com um programa de exercícios em circuito que dura apenas meia hora. ${ }^{8}$

Questionadas quanto ao fato da Curves constituir-se como uma academia só para mulheres, suas alunas confirmam preferir se exercitarem somente entre mulheres e que se sentem com mais liberdade para tal.

Bom também! Fico mais à vontade. Ninguém fica te observando se você possui ou não coordenação motora (Aluna 2).

Acho bom. Sinto uma maior liberdade de se expressar (Aluna 5). 
Excelente. Se bem que poderiam por um caubói aqui para nos animar também! (risos). Acho muito bom. Venho despreocupada (Aluna 6).

No que se refere à demanda de significativa parcela do segmento feminino pela opção de exercitação rápida, a Curves, além de se apresentar como uma academia só para mulheres, inova ainda no treinamento, através de um circuito fast fitness, com um método de 30 minutos de exercício físico, três vezes por semana, projetado especialmente para mulheres, com o objetivo de emagrecimento e aumento da massa muscular. Destarte, somando-se à segmentação feminina, a Curves demarca como um diferencial da empresa a venda de uma prática corporal específica para mulheres que queiram perder peso, medidas e ter um aumento relativo de massa muscular gastando pouco tempo do seu dia. "Ansiosa pelo dinheiro, a mercadoria é criada na produção capitalista à imagem da ansiedade do público consumidor" (HAUG, 1997, p. 35).

\section{FITNESS EXPRESS}

Uma das principais qualidades divulgada como um diferencial da Curves é a sua metodologia de treinamento aeróbico combinada ao treino de força muscular numa única sessão de apenas 30 minutos, três vezes por semana. Trata-se de um sistema, rápido, eficiente e eficaz, ideal tanto para a mulher moderna e independente, com uma agenda sempre cheia de compromissos, como para a dona de casa, repleta de afazeres domésticos e obrigações familiares, conforme propagandeia a própria academia.

Muitas das nossas sócias dizem que seu tempo na Curves são os 30 minutos mais rápidos da semana! A alegria, as risadas, as conversas e a atenção especial que você encontra numa típica academia Curves é diferente de qualquer outro centro de condicionamento físico. ${ }^{9}$

Além dos aspectos que envolvem a animação, outro diferencial propagado, o valor de uso prometido dos serviços vendidos pela Curves é o resultado rápido, bem como a adequação personalizada à aceleração dos ritmos e processos diários ditados pela cotidianidade contemporânea.

Você chega à academia e a recepcionista sabe o seu nome. O vestiário, limpinho e cheiroso, nunca está lotado. Roupa não é problema: até a tur- 
ma do camisetão é bem recebida. E como não tem homem no recinto, ser alvo do olhar crítico de um bonitão sarado está fora de questão. $\mathrm{Na}$ sala de ginástica, cerca de 16 equipamentos estão dispostos em círculo. A professora vai colocá-la num deles ou pedir para que faça primeiro um aquecimento. Os aparelhos de musculação são fáceis de usar. Para seguir seu programa, basta acompanhar uma gravação que comanda a hora de trocar de estação. Entre um equipamento e outro, você também vai passar por plataformas ou minicamas elásticas. Nelas, são feitos os exercícios aeróbicos. O circuito todo é repetido uma ou duas vezes. As professoras geralmente duas ficam no meio do círculo, atentas a tudo e mantendo o alto-astral das alunas. Você não precisa disputar a atenção delas. De sete em sete minutos, a música pára e você mede a freqüência cardíaca, para saber se está trabalhando no ritmo certo para queimar gordura. Como o tempo em cada estação é curto de 30 a 55 segundos, você tem que se concentrar. Não dá para ficar comparando a sua performance com a das colegas. E como não há espelhos, você não vai se aborrecer com a imagem de uma gordurinha sobrando aqui ou acolá... Nesse embalo, a meia hora passa tão depressa que você nem percebe. Mais alguns minutos para o alongamento e é só tomar uma ducha para tocar a vida, com a sensação de missão cumprida. Sensacional: esse pacote permite que você encaixe a ginástica na sua agenda, por mais lotada que ela seja. ${ }^{10}$

Ocorre que tanto a escolha dos exercícios como a ordem dos mesmos podem influenciar o estímulo aplicado. Para o treinamento aeróbio é importante considerar a quantidade total de massa muscular envolvida na modalidade. Considera-se que os exercícios de ação geral, que envolvem mais de dois terços da massa muscular, são mais eficientes para o desenvolvimento de órgãos e sistemas funcionais. Entre os exercícios mais utilizados estão caminhada, corrida, natação e ciclismo, o que parece não ser a realidade do programa - plataformas ou minicamas elásticas utilizadas no método de circuito, com duração de 30 a 55 segundos em cada estação. Da mesma forma, o volume de treino torna-se importante para a melhora do rendimento aeróbio, pois estímulos com duração inferior a 20 minutos ou com freqüência semanal abaixo de duas sessões, geralmente são insuficientes para a melhora do rendimento aeróbio (DENADAI; GRECO, 2005). ${ }^{11}$

Não é de se estranhar, portanto, que quando questionadas sobre a opção pela Curves e a validade do sistema de 30 minutos por dia, três 
vezes por semana, é unânime entre as alunas a avaliação quanto às vantagens e à motivação que o mesmo proporciona.

Já freqüentei academia. Perdia muito tempo. 30 minutos foi o que me trouxe (Aluna 1).

O lugar é agradável... Gasto pouco tempo e ainda tem uma expectativa diferenciada (Aluna 2).

As outras academias são monótonas. Eu faltava mais do que ia. Gastava um maior tempo também (Aluna 3).

O rapidinho! O melhor é isso e por só ter mulher! (Aluna 6).

O sistema da Curves consiste, deste modo, numa espécie de circuito fast fitness, que é uma forma de treinamento onde os exercícios são executados sem intervalo entre um e outro, com 16 estações de equipamentos de resistência hidráulica e estações de movimentação. Foi desenvolvido sobre equipamentos de resistência de fácil utilização e projetados especialmente para mulheres. Como não há necessidade de se trocar pinos ou anilhas de peso, nada precisa ser configurado durante o circuito. Assim, as alunas não podem, de modo algum, colocarem-se estáticas. As novas alunas são acompanhadas a cada estação do circuito pela professora apenas no primeiro dia, numa aula de demonstração previamente agendada. Já nas aulas subseqüentes, as alunas, agora experientes, são orientadas para mudar de estação através de uma gravação reproduzida através de um CD-Rom de áudio, que assume o comando de voz na troca de estações durante os 30 minutos de circuito.

O Ciclo de Treinamento Curves é uma série de atividade física completa que inclui todos os cinco elementos necessários para um perfeito resultado: aquecimento, exercício aeróbico, fortalecimento muscular, resfriamento e alongamento. O nível de resistência se adapta a cada usuária, permitindo a execução do Ciclo de Treinamento de forma cômoda e segura. Você empurra e depois puxa - melhor do que levantar e abaixar pesos. Dessa forma reduz-se a possibilidade de dores e lesões. Nossa atividade física sem impactos, além de segura, ajuda a manter uma boa densidade óssea e combate a osteoporose. Fortalecer os músculos ajuda no equilíbrio das articulações, que é parte fundamental do tratamento da artrite. A Curves oferece um treinamento de força muscular que as mulheres podem fazer. Mulheres de qualquer idade podem 
exercitar-se em nossos aparelhos. Eles são ajustáveis a qualquer nível de preparo físico. Temos membros com menos de 12 anos e até com mais de 105 anos de idade. ${ }^{12}$

Observando com um pouco mais de atenção, a metodologia utilizada na Curves é um circuito de treino no qual os equipamentos são feitos em sistema hidráulico, onde a forma correta de execução é puxando e empurrando o equipamento, exercitando músculos agonistas e antagonistas. Nesse sentido, a utilização de equipamentos guiados favorece a prática de alunos iniciantes, em virtude das trajetórias definidas desses equipamentos (UCHIDA et al., 2003). Entretanto, o fato de não haver pinos ou anilhas de peso para ajustar a intensidade de treino para cada aluna, bem como, regular o equipamento para as necessidades corporais de cada um, torna-se um fator limitante. Com isso o treino de força prescrito pela Curves é um treino de resistência de força realizado com o método de treinamento em circuito. $\mathrm{O}$ método em circuito baseia-se na execução de vários exercícios, sem intervalos ou com pequenos intervalos entre eles, definindo o número de exercícios, número de repetições e número de passagens conforme o objetivo e grau de treinabilidade do praticante (UCHIDA et al., 2003; FLECK; KRAEMER, 1999), o que parece não acontecer na Curves, tendo em vista que o número de exercícios e o tempo de execução já foram previamente definidos. ${ }^{13}$

O nível de intensidade do treino é observado de sete em sete minutos, quando há uma gravação no $C D$-Rom solicitando às alunas pararem e aferirem sua pulsação. A gravação marca o tempo de contagem e avisa quando começar e quando parar a contagem. Após isso as sócias calculam seu batimento cardíaco e lêem numa tabela fixada na parede da academia em qual zona alvo ela está. Novamente a gravação indica se deve ou não passar para a próxima estação. E assim segue o circuito de treino. Todavia, a freqüência cardíaca é apenas uma das formas de controlar a intensidade do treino, tendo sua maior utilização nos programas aeróbios. Entretanto, para o treinamento de força existem outras formas de controlar a intensidade do treino que talvez possam propiciar um maior controle das variáveis do treinamento, tais como aumentar ou diminuir o peso nos exercícios, aumentar ou diminuir o intervalo entre as séries, aumentar ou diminuir a velocidade de execução do movimento (UCHIDA et al., 2003). 
Outra crítica em relação à metodologia adotada pela Curves diz respeito aos princípios que norteiam o treinamento. $\mathrm{O}$ controle das cargas de treinamento possibilita quantificar os estímulos de treino, individualizando e proporcionando para os praticantes respostas mais homogêneas e adequadas aos seus objetivos. Entende-se a adaptação como um processo de auto-regulação do organismo que se modifica morfológica e funcionalmente reagindo aos estímulos dados, pois ao alterar sua rotina anterior, geralmente sedentária, o corpo das alunas responde aos novos estímulos aumentando capilares sanguíneos e aumentando o volume muscular. Isso não é efetivado se após o período de adaptação, o estímulo continua o mesmo. E é justamente neste momento que a metodologia de treino da Curves perde sua eficiência e eficácia, pois não há alterações no ritmo e no circuito projetado pela academia. Com isso, o princípio da sobrecarga ${ }^{14}$ se verifica, dificultando ou inviabilizando os objetivos preconizados pelo sistema Curves de emagrecimento e aumento de massa muscular. Outro princípio do treinamento, o da individualidade biológica, também se faz ausente. Afinal, na Curves, o treino é generalizado, não respeitando assim indivíduos que necessitam de um estímulo maior ou menor para que o treino seja eficiente e eficaz.

Mas se o treino tem eficiência e eficácia duvidosa a partir de um dado período, produzindo um efeito muito mais de manutenção dos resultados atingidos do que propriamente continuidade no ganho de capacidade aeróbica e força muscular, isto nos leva a questionar as estratégias que garantem a freqüência e a permanência das alunas na Curves. Além da pseudo-sensação de bem-estar, saúde e beleza produzida, ${ }^{15} \mathrm{o}$ processo de persuasão, comum às cartilhas de marketing para academias, decifra parte do enigma:

Quanto mais forte for o conteúdo emocional em nossas estratégias de marketing, melhores serão os resultados. Persuadindo, estaremos auxiliando alguém a tomar uma decisão. Se fornecermos uma base racional suficientemente coerente e se formos habilidosos para carregar nossas estratégias de fundo emocional, de modo convincente, obteremos êxito (LEITE, 2000, p. 15).

Secundariza-se, portanto, a base de legitimação racional tecnocientífica e acrescem as inovações criativas de base emocional. 


\section{TÉCNICAS DE RETENÇÃO}

O processo de modernização da gestão e organização do trabalho num mercado considerado até então tradicional - qual seja, o mercado do fitness -, é altamente dependente de fatores como a inovação. Parece não haver alternativa diante da alta competitividade estimulada pelo desenvolvimento desregrado do setor, bem como solução possível ante o crescimento vegetativo que apanha várias academias, limitando a expansão ou determinando a mortalidade do negócio. "Nesse cenário, a opção pela diferenciação por meio da inovação surge como uma das principais estratégias competitivas de que as organizações lançam mão, distinguindo-se dos concorrentes" (PINHEIRO; PINHEIRO, 2006, p. 8). No caso da Curves, tanto a segmentação feminina como sua metodologia de treinamento constituem iniciativas de inovação e criatividade. Todavia, estas parecem atuar muito mais na atração de novas alunas do que propriamente na retenção das veteranas, o que não inibe uma tendência comum a toda academia, a alta rotatividade dos alunos que se traduz por índices de desistência bastante elevados. ${ }^{16}$ Assim, para a retenção, outras estratégias se fazem necessárias, as quais, no caso da Curves, merecem atenção, pela criatividade e peculiaridade, as técnicas de inovação monetária, inovação carismática e inovação solidária.

O que estamos chamando de inovação monetária é expressão de um processo diretamente relacionado ao que Marx (1971) denominou fetichismo da mercadoria. São deste processo que provêm as ilusões e sutilezas que velam à consciência do consumidor as contradições do sistema monetário. Neste ínterim, dado que as práticas corporais mercantilizadas apresentam-se cada vez mais como mera abstração de uma promessa, de um valor de uso prometido - isto é, saúde e embelezamento, por exemplo -, a relação de troca em questão torna-se uma relação na qual somente interessa a forma da mercadoria, sua manifestação sensível, não o seu conteúdo racional, pois este acaba por ser secundarizado. Vale, sobretudo, seu apelo emocional. Mas no caso da Curves, como se não bastasse, com sua técnica de inovação monetária, a aparência enganadora que recobre a relação de troca no processo de compra e venda de seus serviços vai ainda mais longe.

Na relação de compra e venda que se opera na Curves, o equivalente universal, a mercadoria-dinheiro assume uma forma dissimulada. 
Assim, o processo da troca se estabelece na ausência de um acontecer formal, confundindo as fronteiras que identificam quem vende e quem compra o serviço da academia. Senão, vejamos: O primeiro contato da Curves com suas potenciais alunas é mediado pelo tele-marketing, que é feito pela recepcionista. Os números de telefones geralmente são divulgados pelas alunas veteranas. Nesta abordagem, a recepcionista agenda uma visita da potencial aluna a Curves, cuja apresentação é feita pessoalmente pela professora. Assim, para que a futura aluna venha a aderir ao plano da academia, lhe é explicado em detalhes o sistema e os métodos da Curves. Há de se dizer que, concretizando sua adesão, as alunas são doravante consideradas sócias da Curves e ganham um cartão do Clube de Vantagens Curves, podendo ainda freqüentar qualquer uma das unidades franqueadas da Curves. A relação de troca é, por conseguinte, conduzida pelas professoras de cada unidade, exaltando a eficiência e eficácia da metodologia de treinamento da Curves no que diz respeito ao ganho de força e capacidade aeróbica, mas destacando o que toca o desejo e as fraquezas das alunas - isto é, sócias -, a saúde e o embelezamento do corpo.

É explicada ainda às novas sócias uma outra inovação da academia, o Curves Cash, uma espécie de unidade de crédito reutilizável na compra de produtos exclusivos da linha da academia que contribuem para a difusão da marca Curves. Se a aluna se exercitar apenas três vezes por semana, recebe determinada quantidade de créditos; quando indica futuras sócias e estas efetivam seus planos, recebem créditos; se a mesma participa das aulas especiais, recebe uma quantia de Curves Cash; se a sócia perde medidas e peso, cada qual com sua tabela específica, também recebe créditos em função da quantidade em centímetros perdidos. Com isso, o significado implícito dado ao Curves Cash está em aproximar a sócia a uma realidade aparente sobre a qual se assenta a própria noção de pertencimento ao "clube" Curves. Uma vez sócias, recebem uma parte do dito "lucro" através de produtos exclusivos e outros benefícios do Clube de Vantagens Curves. Deste modo, com o inventivo associativismo propalado pela noção de clube que recobre os interesses mercantis da Curves, forja-se um sentimento de pertencimento e identidade que acaba por velar a relação de troca que está na base do consumo de práticas corporais mercantilizadas. Para as alunas, parece ficar em segundo plano se o que praticam está sendo eficiente ou 
não, pois se sentem alegres e revigoradas ao irem para a "sua" academia, exercitando-se em um clube em que são sócias.

No que diz respeito à inovação carismática, é esta que garante o sentimento de alegria e revigoramento que apanha as sócias do clube. A preocupação com o carisma a ser transmitido pelas professoras funciona como elemento central nos processos prazerosos de estimulação emocional deflagrados pela Curves. É certo que as alunas muitas vezes procuram a Curves pelo fato de esta ser uma academia só para mulheres, sentindo-se mais à vontade diante da ausência homens. Mas a animação do ambiente é que garante a motivação a sua permanência. $\mathrm{E}$ a animação está sob o encargo das professoras e das aulas especiais, que são aulas para comemorar algo. Além disso, as professoras organizam ainda uma série de jogos e brincadeiras com as sócias. A motivação verbal também é importante, desde que não atrapalhe a música, pois é obrigação das professoras não deixar que as alunas estacionem nas estações de movimentação do circuito. A própria Curves assume uma concepção que requalifica a função das professoras, privilegiando a animação interna ao ambiente da academia como mais um de seus diferenciais.

Muitas das nossas sócias dizem que seu tempo na Curves são os 30 minutos mais rápidos da semana! A alegria, as risadas, as conversas e a atenção especial que você encontra numa típica academia Curves é diferente de qualquer outro centro de condicionamento físico que você já possa ter visitado. ${ }^{17}$

Quando da pergunta acerca do recurso da animação inerente ao ambiente da academia, as alunas são categóricas ao afirmarem as vantagens e o prazer proporcionado pela Curves.

Essa agitação das comemorações! Tira o stress da gente (Aluna 1).

Essas festinhas que tiram o stress. Acho bom. Sinto uma maior liberdade de se expressar (Aluna 4).

Brincadeira! Sinto mais disposição. Aqui a aula é mais descontraída... mais prazerosa (Aluna 5).

Aqui é mais descontraído... Cheio de brincadeiras. Não sei. Gosto de vir pra cá pra relaxar... Conversar... (Aluna 6).

No que diz respeito às relações pedagógicas subjacentes à técnica da inovação carismática, há uma perda de autonomia quanto ao 
papel das professoras, que assumem a função de reprodutoras de um programa preestabelecido, que substitui o trabalho educativo, impedindo-as de interferir na rotina de exercícios propostos às suas alunas. A tecnologia utilizada substitui o papel docente das professoras, tornando seu trabalho rígido e acrítico, não exigindo da mesma uma ação teleológica relacionada ao planejamento do trabalho a ser realizado. As mesmas devem apenas se atentar para advertências de ritmo e correções posturais durante a sessão de treino, estimulando, corrigindo, trocando o $C D$-Rom e animando as sócias durante a prática. Limitam-se apenas à função unilateral da animação. ${ }^{18}$ Ao ganhar tal atribuição, seja ecoando frases feitas para a motivação das alunas, seja travestidas para as aulas especiais, seja com a apresentação de novas brincadeiras, seu trabalho é esvaziado de conteúdo verdadeiramente educativo.

E finalmente, ao nos referimos à inovação solidária, estamos chamando atenção para as campanhas filantrópicas organizadas pela Curves. Esta iniciativa faz parte da propaganda em torno da responsabilidade social da academia, que faz quatro campanhas anuais: prevenção ao câncer de mama, arrecadação de alimentos, de agasalhos e de brinquedos. Ocorre que as campanhas não funcionam com doações simplesmente. Para que as alunas ou outras pessoas participem, a academia incentiva com descontos na adesão ao Clube Curves e com créditos em Curves Cash para quem é aluna. Ainda que realmente preocupada com o bem-estar e a melhoria das condições de vida da população, organizando projetos de ação social, a Curves parece mesmo é buscar agregar valor à sua marca, interessada no marketing social e capital simbólico acumulado em torno da idéia de "empresa cidadã", bem como estimular a atração de novas alunas e retenção das que já pertencem ao seu quadro de sócias.

\section{CONSIDERAÇÕES FINAIS}

Conforme a análise construída até aqui, um dos grandes desafios - senão o maior deles - imputados às academias de ginástica pelo competitivo mercado do fitness diz respeito à superação da alta rotatividade no consumo das práticas corporais. Isto demanda investimento permanente do setor em técnicas de inovação tanto no que se refere à atração de novos clientes como na retenção daqueles já conquistados. Deste modo, segundo Leite (2000, p. 14-15), 
As ações empresariais estarão sempre tendo como foco atrair e manter alunos. Vamos aprender a atraí-los, mas, principalmente, em tempos de alta competitividade, precisamos aprender a segurá-los. E qual o melhor jeito de segurá-los? Com emoção, dando uma base racional para escolha.

No caso da Curves Brasil, a base racional e legitimadora para a opção pela academia está na sua metodologia inovadora, pensada e organizada especificamente para o público feminino - neste ínterim, a estratégia da segmentação atua também como forte apelo emocional -, de treinamento aeróbico combinada ao treino de força muscular numa única série de apenas 30 minutos, três vezes por semana. É justamente o que atrai sua clientela. Quanto à retenção, de acordo com o mesmo autor, há de se "fornecer uma quantidade suficiente de conteúdo emocional para que nossos alunos não apenas se liguem em nós, mas que passem a crer que não poderão freqüentar outra academia". É o objetivo que a Curves consegue atingir, em certa medida, através de suas técnicas de inovação monetária, carismática e solidária.

Acontece que as técnicas de inovação não demandam somente criatividade por parte dos proprietários de academia, cobram, sobretudo, investimentos. Na concepção de um novo modelo de negócios, o sistema de franquias, seguindo a tendência da monopolização do setor, não só permite o ajuste do setor à realidade do mercado globalizado, através da distribuição e padronização em escala de técnicas de inovação, como acaba por contribuir com os processos de concentração e centralização que conferem forma a uma grande cadeia industrial. E no que se refere ao sistema de franquias, parecem surgir novos atores no mercado do fitness, quais sejam, "o franqueador internacional, o nacional, indústrias de marcas e grifes associadas aos mais variados produtos e acessórios, bem como produtores de equipamentos dedicados, todos disputando clientes globais." (PINHEIRO; PINHEIRO, 2006, p. 1920). Modifica-se, assim, o conjunto das relações que se estabelecem e envolvem o ambiente das academias de ginástica.

No âmbito do lazer e das práticas corporais, portanto, os números e as técnicas de inovação chamam atenção para a importância do segmento do fitness, cujo crescimento e transformação demonstra ser uma tendência mundial. Neste universo, seja em Goiânia, São Paulo ou Nova Iorque, 
não só as práticas corporais mercantilizadas, mas também corpos, odores, músicas, espaços, equipamentos, roupas, calçados, acessórios, alimentos e vários outros produtos e serviços carregam os traços e evidências de um envolvente processo que se espalha pelo mundo, definindo formas de sociabilidade, amoldando subjetividades, modificando e definindo hábitos, valores e comportamentos. Trata-se de uma tendência que coincide com o processo de mundialização da cultura, o que, segundo Ortiz (2000), ocorre quando um conjunto de manifestações e expressões culturais - no caso específico da Indústria do Fitness, o objeto é a cultura corporal -, embora bastante diverso, passa a operar sobre uma base material, tecnológica e econômica comum, o próprio mercado globalizado.

Flexible accumulation, innovation techniques, and the fitness industry: the Curves Brasil case study

\begin{abstract}
This text presents an investigation about the characteristics and trends in flexible accumulation that push de development of the fitness market. This study examines the case of Curves Brasil. To do so, we tried to confront and examine the implementation of organizational techniques with tested efficacy in a global scale through the verification of a particular and real case of development. Our conclusions point to new innovation techniques being currently used to solve the difficult equation faced by this sector with regards to attracting and retaining customers.
\end{abstract}

KEYWORDS: leisure - culture - education - Physical Education - gyms.

Acumulación flexible, técnicas de innovación y gran industria del fitness el caso Curves Brasil

\title{
RESUMEN
}

Este texto presenta los resultados de una investigación relativa a las características y las tendencias de la acumulación flexible que engloban el desarrollo del mercado del fitness. Se trata de un estudio de caso de Curves Brasil, para el cual buscamos enfrentar y examinar la implantación de técnicas organizacionales que han evidenciado ya eficacia en escala mundial con el principio de la verificación de un caso particular y real de desarrollo. Las conclusiones señalan nuevas técnicas de innovación utilizadas para resolver la difícil ecuación que hecha frente al sector en lo que respecta a la atracción y la retención de consumidores.

PALABRAS-CLAVE: ocio - cultura - educación - Educación Física - academias de la gimnasia.

254 MASCARENHAS, F. et al. Acumulação flexível, técnicas de inovação ... 


\begin{abstract}
NOTAS
1 Para saber mais sobre a intensificação da mercantilização do lazer a partir da década de 1990, ver Mascarenhas (2005).

2 O modelo de acumulação flexível, segundo Harvey (2000), se caracteriza pela flexibilidade dos processos de trabalho, produtos e padrões de consumo, reestruturação produtiva, mercadorização de bens culturais, fusões empresariais, centralização de capitais, privatizações de empresas estatais e globalização de mercados. Tais ações permitem versatilizar as transações econômicas, possibilitando um maior acúmulo de capital.

3 A partir do estudo da Curves Brasil, através do princípio da verificação de um caso particular e real de desenvolvimento, buscamos confrontar e examinar a implementação de formas de gestão que já têm sua eficiência e eficácia evidenciadas pela Indústria do Fitness em escala mundial. Nesta direção, foi realizada pesquisa documental a partir de material publicitário e de divulgação referente a Curves, além de estudo junto à uma das unidades da Curves no Brasil que, entre os meses de outubro e novembro de 2006, concretizou-se por quatro sessões de observação, bem como entrevistas semi-estruturadas realizadas junto a seis alunas da academia.

4 A título de exemplo, segundo levantamento da ACAD, em 2001, existiam 7.012 estabelecimentos focados em produção do fitness no Brasil. Deste universo, 94\% podiam ser consideradas academias de pequeno porte, totalizando um faturamento inferior a $\mathrm{R} \$ 1$ milhão. Por sua vez, a maior academia do país à época, a Runner, de São Paulo-SP, dispôs no mesmo ano de 24.000 alunos e faturou, sozinha, aproximadamente R $\$ 25$ milhões, ou seja, vinte e cinco vezes mais que o total da Pequena Indústria do Fitness (KASZNAR \& GRAÇA FILHO, 2002). Há de se dizer ainda que a distinção entre pequenas e grandes academias, para fins de classificação de amostra de pesquisa, está presente também em Hansen e Vaz (2004).

5 "Uma franquia empresarial é um sistema pelo qual um franqueador sede ao franqueado o direito de uso da marca ou patente, associado ao direito de distribuição exclusiva ou semi-exclusiva de produtos ou serviços e, eventualmente também ao direito de uso de tecnologia
\end{abstract}


de implantação e administração do negócio ou sistema operacional desenvolvidos ou detidos pelo franqueador mediante a remuneração direta ou indireta" (BRASIL, 1994, art. $2^{\circ}$ ). No caso específico do mercado do fitness, para saber mais sobre a combinação da organização científica do trabalho em academias de ginástica com o sistema de franquias, consultar Pinheiro e Pinheiro (2006).

6 Dados extraídos do site de divulgação da Curves Brasil. Disponível em: <http://www.curves.com.br/sobreacurves.shtml>. Acesso em 19 nov. 2006.

7 Podemos dizer que, desde pequenas, espera-se que as mulheres adotem certos hábitos e padrões de comportamento relacionados ao cuidado com o corpo. "A socialização das meninas é construída sobre um corpo frágil, passivo, desprovido de força, onde a beleza física é fundamental. Nos meninos, ao contrário um corpo forte, agressivo, viril é o mais estimulado" (PAIM; STREY, 2004, p. 2).

8 Extrato da matéria "Malhação para mulheres, só em meia hora", da Revista Feminíssima. Disponível em: <http://www2.uol.com.br/feminissima/index.shtml>. Acesso em: 20 nov. 2006.

9 Afirmativa constante do site de divulgação da Curves Brasil. Disponível em: <http://www.curves.com.br/sobreacurves.shtml>. Acesso em 19 nov. 2006.

10 Trecho matéria "Malhação só para mulheres", da Revista Boa Forma. Disponível em: <http://boaforma.abril.com.br/edicoes/216/fechado/ Fitness/conteudo_11.shtml>. Acesso em: 20 nov. 2006.

11 A intensidade de treino é um componente que possibilita determinar o tipo de substrato energético oxidado, os tipos de fibras musculares envolvidas no trabalho e a quantidade de massa muscular envolvida na atividade. A razão de troca respiratória $(\mathrm{R})$ pode sinalizar qual substrato energético oxidado na atividade, a oxidação das gorduras resulta em um $\mathrm{R}$ de 0,7 e dos carboidratos em um $\mathrm{R}$ de 1,0 , portanto, exercícios de baixa intensidade tendem a favorecer a oxidação das gorduras. Porém, para que o R seja utilizado como estimativa da utilização do substrato durante a atividade, o indivíduo deve ter atingido um estado estável no exercício (POWERS; HOWLEEY, 2000), o que parece não acontecer na metodologia adotada pela Curves. 
12 Informações constantes do site de divulgação da Curves Brasil. Disponível em: $<$ http://www.curves.com.br/sobreacurves.shtml $>$. Acesso em 19 nov. 2006.

13 A melhora do consumo máximo de oxigênio $\left(\mathrm{VO}_{2 \text { máx }}\right)$ é relatada por diferentes autores nos programas de treinamento com pesos em circuito - aproximadamente $4 \%$ - $8 \%$ para homens e mulheres, respectivamente - porém bastante inferior aos aumentos do $\mathrm{VO}_{2 \text { máx }}$ obtidos pelos programas tradicionais de condicionamento aeróbio - $15 \%$ $20 \%$-, o que mais uma vez parece depor contra o sistema adotado pela Curves.

14 O princípio da sobrecarga preconiza a aplicação de aumento progressivo na carga de trabalho a partir do momento em que o praticante adaptou-se à carga inicial (MONTEIRO, 2002).

15 Matiello Júnior e Gonçalves (2001), ao realçarem possíveis inconsistências e equívocos assumidos pela maioria das elaborações sobre atividade física relacionada à saúde, já nos alertam para os efeitos e riscos das práticas de atividades físicas como pseudo-sensação de segurança para obter saúde.

16 Conforme pesquisa feita pela Faculdade de Educação Física da USP, citada pela Revista da Folha, na matéria "Tédio, suor e calorias" o aluno "ioiô" - isto é, aquele que vai e volta - representa a maioria dos consumidores do mercado do fitness. Os dados revelam que $82 \%$ dos alunos das academias já desistiram pelo menos uma vez de praticar exercícios, alegando falta de tempo ou de motivação. A taxa de rotatividade nesses estabelecimentos chega a 50\%. Disponível em: $<$ http:// www1.folha.uol.com.br/revista/rf3005199901.htm>. Acesso em: 20 nov. 2006.

17 Extrato de material de propaganda constante do site de divulgação da Curves Brasil. Disponível em: $<$ http://www.curves.com.br/sobreacurves.shtml>. Acesso em: 19 nov. 2006.

18 A animação a que nos referimos aqui está muito mais ligada à ambientalização da academia como um espaço alegre e divertido de convívio e exercitação, produzida pelo bom humor e cordialidade muitas vezes artificiais das professoras, do que à animação como processo de organização da cultura e de educação estética no âmbito das práticas de lazer. 


\section{REFERÊNCIAS}

ADORNO, T. W.; HORKHEIMER, M. A indústria cultural: o esclarecimento como mistificação das massas. In: Dialética do esclarecimento: fragmentos filosóficos. Rio de Janeiro: Jorge Zahar, 1985. p. 113-156.

BRASIL. Presidência da República. Casa Civil. Subchefia para Assuntos Jurídicos. Lei no 8.955, de 15 de Dezembro de 1994. Brasília, 1994. Disponível em: <http://www.planalto.gov.br/CCIVIL/Leis/L8955. htm>. Acesso em: 19 nov. 2006.

COSTA, L. P. da. (Org.). Atlas do esporte no Brasil. Rio de Janeiro: Shape, 2005.

DENADAI, B. S.; GRECO, C. C. Prescrição do treinamento aeróbio: teoria e prática. Rio de Janeiro: Guanabara Koogan, 2005.

FLECK, S.; KRAEMER, W. Fundamentos do treinamento de força muscular. 2. ed. Porto Alegre: Artmed, 1999.

HANSEN, R.; VAZ, A. F. Treino, culto e embelezamento do corpo: um estudo em academias de ginástica e musculação. Revista Brasileira de Ciências do Esporte, Campinas, v. 26, n. 1, p. 135-152, set. 2004.

HARVEY, D. Condição pós-moderna. Uma pesquisa sobre as origens da mudança cultural. 9. ed. São Paulo: Loyola, 2000.

HAUG, W. F. Crítica da estética da mercadoria. São Paulo: UNESP, 1997.

KASZNAR, I.; GRAÇA FILHO, A. O esporte como indústria: solução para criação de riqueza e emprego. Rio de Janeiro: CBV, 2002.

LEITE, J. A. Academias: estratégias para o sucesso. Rio de Janeiro: Sprint, 2000.

MARX, K. O capital. Crítica da economia política. Livro 1, v. 1. Rio de Janeiro: Civilização Brasileira, 1971.

MASCARENHAS, F. Entre o ócio e o negócio: teses acerca da anatomia do lazer. 2005. 308 f. Tese (Doutorado em Educação Física) - Faculdade de Educação Física, Universidade Estadual de Campinas, Campinas, 2005.

258 MASCARENHAS, F. et al. Acumulação flexível, técnicas de inovação ... 
MATIELLO JÚNIOR, E.; GONÇALVES, A. Entre a bricolagem e o personal training, ou... a relação atividade física e saúde nos limites da ética. In: CONGRESSO BRASILEIRO DE CIÊNCIAS DO ESPORTE, 12., Caxambu. Anais... Caxambu: CBCE, 2001. p. 1-10.

MÉSZÁROS, I. Para além do capital. Rumo a uma teoria da transição. Campinas: Unicamp; São Paulo: Boitempo, 2002.

MONTEIRO, A. G. Treinamento personalizado: uma abordagem didático-metodológica. 2. ed. São Paulo: Phorte, 2002.

ORTIZ, R. Mundialização e cultura. São Paulo: Brasiliense, 2000.

PAIM, M. C. C.; STREY, M. N. Corpos em metamorfose: um breve olhar sobre os corpos na história, e novas configurações de corpos na atualidade. Lecturas educación física y deportes, Buenos Aires, n. 79, p. 1-9, dez. 2004.

PINHEIRO, I. A.; PINHEIRO, R. R. Organização científica do trabalho reinventa um mercado tradicional: o caso do fitness. RAE-eletrônica, São Paulo, v. 5, n. 2, p. 1-26, dez. 2006.

POWERS, S.; HOWLEY, E. Fisiologia do exercício: teoria e aplicação ao condicionamento e ao desempenho. 3. ed. São Paulo: Manole, 2000.

SILVA, A. M. Corpo, ciência e mercado: reflexões acerca da gestação de um novo arquétipo da felicidade. Campinas: Autores Associados; Florianópolis: UFSC, 2001.

UCHIDA, M. C. et al. Manual de musculação: uma abordagem teóricoprática ao treinamento de força. São Paulo: Phorte, 2003.

Recebido: 15 de março de 2007

Aprovado: 18 de abril de 2007

Endereço para correspondência: fernando.masca@uol.com.br 